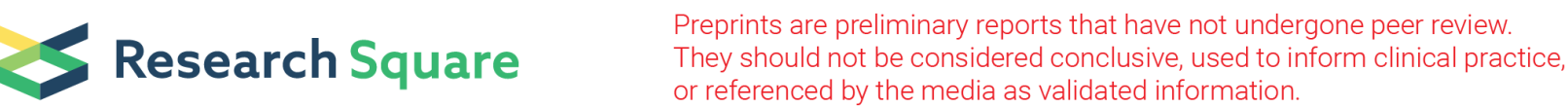

\section{The Influence of Prolonged High Altitude Deployment on Psychomotor Functions Among Chinese Military Plateau Motor Vehicle Operators: Does Deployment Duration Matter?}

\author{
Zhi-hao Tu \\ Second Military Medical Universuty \\ Li Peng \\ Second Military Medical University \\ Jing-wen He \\ Second Military Medical University \\ Xing-hua Shen ( $\sim$ shenxhsci@sina.com )
}

\section{Research}

Keywords: High altitude, Psychomotor functions, Hypoxia, Fine motor dexterity, Reaction time, Bimanual coordination, Eye-hand coordination

Posted Date: June 9th, 2020

DOI: https://doi.org/10.21203/rs.3.rs-33437/v1

License: (c) (i) This work is licensed under a Creative Commons Attribution 4.0 International License.

Read Full License 


\section{Abstract}

Background:Psychomotor functions are necessary for Chinese military plateau motor vehicle operators (PMVOs) to complete their driving tasks. This study aimed to investigate (1) the influence of chronic exposure to high altitude (HA) on psychomotor functions among PMVOs; (2) whether deployment duration at HA moderated the effect of HA.

Methods: 196 male PMVOs in Golmud (average altitude: 2,890 m) and 192 male lowland motor vehicle operators (LMVOs) were recruited as the studygroup (HA group) and control group (LA group). Both groups were in turn categorized into 3 groups by deployment duration: Group A (less than 1 year), Group B (between 1 year and 2 years), and Group C (more than 2 years). All participants completed simple reaction time, bimanual coordination test, fine motor dexterity test, and eye-hand coordination test. Between-altitude and deployment duration differences were explored usinganalysis of variance (ANOVA).

Results: HA group participants had slower simple reaction time in comparison to $\operatorname{LA}$ group $(F(1,387)=$ $\left.18.041, p<0.001, n_{p}^{2}=0.045\right)$. HA group needed less time to complete the bimanual coordination test $\left(F(1,387)=2295.648, p<0.001, \eta_{p}{ }^{2}=0.857\right)$. HA group had more error times in fine motor dexterity test $\left(F(1,387)=5.980, p=0.015, \eta_{p}{ }^{2}=0.015\right)$. HA group participants had better left aim index $(F(1,387)=$ $\left.13.205, p<0.001, \eta_{p}^{2}=0.033\right)$ and more right hits $\left(F(1,387)=3.916, p=0.049, \eta_{p}^{2}=0.010\right)$ in aiming test. The interaction effect of altitude and duration was significant on hit number with left hand in the tapping test $\left(F(2,387)=3.327, p=0.037, \eta_{p}{ }^{2}=0.017\right)$. Butsimple effect analysis showed that the effect of duration was not significant among HA group $(p=0.129)$.

Conclusions: In this study, we found that prolonged exposure to HA may cause psychomotor slowing and declining fine motor dexterity. But, the moderating effect of deployment duration was not supported by this study.

\section{Background}

China has more than 3000 kilometers of national borderline on the plateau, mostly on the Tibet plateau. For China, Tibet plateau is of great military strategic value. Chinese military plateau motor vehicle operators (PMVOs) station at Golmud (average altitude: 2,890 m). Their duty is to operate cargo carrying wheeled vehicles into Tibet (average altitude along the way: $>4000 \mathrm{~m}$ ) to supply border posts with military material six times a year (lasting about 10 days per duty). According to China's military service system, these PMVOs must serve there for at least 2 years. However, many of them choose to continue serving there for honor after two-year compulsory service period. The route into Tibet is full of difficulties and dangers, so completion of this transportation duty requires superb driving ability. Psychomotor functions are good indicators of driving ability [1]. Abundant studies have demonstrated that impairment of psychomotor functions were associated with impaired driving abilities[2-5]. Poor driving ability means the transportation mission will fail and the safety of drivers themselves will be seriously threatened. Thus, 
the effect of prolonged deployment (more than 2 years) at high altitudes (HA) on psychomotor functions among PMVOs is a really important research topic.

Substantive researches showed that a wide range of cognitive systems may be impaired during acute and chronic exposure to HA [6]. However, fewer studies focused on alternations in psychomotor functions with altitude. An earlier published study found that performance of finger-tapping tasks significantly decreased in a simulated HA environment [7]. Bolmont et al. [8] found that psychomotor ability of subjects decreased significantly during acute exposure to HA (simulated climb of Mount Everest in a decompression chamber). A field study shown that HA residents (>3000 $\mathrm{m}$ ) had poorer performance in Hand Movement Test than low altitudes (LA) residents $(0-1,500 \mathrm{~m})$ in a hut at 4,860 $\mathrm{m}$ on Mount Chimborazo [9]. Thus, the adverse effect of acute exposure to HA on psychomotor functions has been recognized [6].

But, when it comes to long-term exposure to HA, the situation becomes rather complex. A considerable body of research compared native HA residents with native LA residents and found cognitive impairments in HA residents [10-12]. In this situation, cultural and genetic differences between the two populations could be confounding factors when inferring about the effect of chronic exposure to HA [6]. In addition, it is problematic to speculate that people who immigrated to HA at their adulthood (like PMVOs) also suffered cognitive and psychomotor deficits based on the results from studies on indigenous residents $[13,14]$. These observed cognitive and psychomotor deficits may result from developmental problems before adulthood rather than impairments caused by chronic exposure to HA after adulthood. For example, several researchers found hypoxia and nutritional deficiencies in infants and children living at HA which might cause cognitive deficits [15]. Hogan et al. [16] found that children and adolescent living at HA had a minor psychomotor slowing. But, another study showed that 7-month residence at moderate altitudes $(2,260 \mathrm{~m})$ of young adults from LA did not cause significant cognitive impairments [17]. Hill et al. [18] observed slower psychomotor speed in digit symbol coding tasks and attention among native HA adolescents and younger adults than control group. But these altitude differences disappeared in the earlier or later life span between two groups. These seemingly contradictory evidence suggested that there may exist a critical period of the effect of HA on psychomotor functions, which means growing children or adolescents are more susceptible to adverse effects of HA than adults.

The adaptive process to HA makes the situation more complex. Most studies suggested that acute exposure to HA can cause cognitive and psychomotor impairments [6]. However, in some other studies, cognitive and psychomotor impairments were not observed after 7-month or 1-year residence at HA [17, 19]. Thus, there may be a strong adaptive process for the brain to compensate for oxygen delivery constraint, which can mask altitude related psychomotor impairments [18]. Further question is how much time the adaptation to HA need to outweigh the adverse effects and when the adaptation process cannot reverse the altitude related impairments. Chen et al. [19] conducted a 2-year panel study with young, healthy undergraduate students from LA. They found that there were no statistically significant differences of accuracy in the Verbal/Visual Memory Test between year one and baseline, but decreased 
accuracy was detected between year two and baseline. These results suggested that 7 months (or earlier) and some time between 1 year to 2 years may be the key points of adaptation process.

In this article, we aimed to investigate: (1) the influence of prolonged high altitude deployment on psychomotor functions among PMVOs; (2) whether deployment duration at HA moderated the effect. To our best knowledge, this was the first study focusing on the effect of long-term HA residence on psychomotor functions and the moderating role of duration among adult residents who lived at HA after adulthood.

\section{Methods}

Subjects and procedure

The present study recruited 196 male PMVOs (HA group) in Golmud (average altitude: 2,890 m) for psychomotor tests. All of them had been living at LA $(<300 \mathrm{~m})$ without any exposure to altitude higher than $500 \mathrm{~m}$ before they were assigned to Golmud. None of them were on duty to Tibet in the recent month. 192 male lowland motor vehicle operators (LMVOs) were recruited as the control group (LA group), who were lowlanders, served at LA $(<300 \mathrm{~m})$ and had not gone to plateau in the recent year. Both groups were further divided into 3 groups based on their deployment duration as a driver: Group A (less than 1 year), Group B (between 1 year and 2 years), and Group C (more than 2 years). All subjects were healthy right-handed Han Chinese without a past history of head injury and neurological disorder.

All subjects were tested in quiet and bright rooms in their own barracks between 8.30 a.m. and 11.30 a.m. in July, 2016. The protocols were approved by the Review Board of the Second Military Medical University. Written informed consent was obtained from each subject before participating in this study.

Measures

Sociodemographic data

The sociodemographic variables include age, service time, educational level, marital status and only child or not. Educational level was categorized as 'Secondary school', 'High school', 'Junior college', and 'Undergraduate or above'. Marital status was categorized as 'Single' or 'Married'. Only child or not was categorized as 'Yes' or 'Not'.

Simple reaction time

The reaction time measuring instrument (model EP708A) produced by Scientific \& Teaching Instruments Factory of East China Normal University (STIFECNU) was used to assess simple reaction time (SRT) (see Fig. 1). The task was to press the button when cued visually by light. The light was on for 20 times in 1 minute. The subjects were told the procedure and practiced once before the formal test. The average reaction time was recorded in second (s). 
The bimanual regulator (model EP711) produced by STIFECNU was used to evaluate the coordination ability of two hands (see Fig. 2). The task was to rotate two knobs simultaneously with left hand and right hand to make the probe go around the orbit twice. Rotating the right knob could make the probe move up and down, while rotating the left knob could make the probe move left and right. The coordinated rotation of both hands ensured that the probe moved in the orbit. Subjects were asked to make the probe turn counterclockwise and then clockwise. The regulator automatically recorded completion time and the times of the probe out of the orbit (error times). The subjects were told the procedure and practiced once before the formal test.

Fine motor dexterity test

The finger dexterity measuring instrument (model EP109) produced by STIFECNU was used to access the fine motor dexterity (see Fig. 3). The subjects were asked to clamp a tweezer by right fingers and use the tweezer to tweeze 100 small short needles into 100 holes one by one. The instrument automatically recorded completion time in second (s) and the observer documented the number $(n)$ of short needles dropped. The subjects were told the procedure and practiced once before the formal test.

Eye-hand coordination test

In this study, two subtests, Aiming and Tapping, in the Motor Performance Series (MLS) of the Vienna Test System (version 8.0; Schuhfried, Austria) were used to access the eye-hand coordination which was quite important to driving (see Fig. 4). Both tests were performed on a standardized work panel (300x $300 \times 15 \mathrm{~mm}$ ). The testing area of "Aiming" was 20 brass rings with a diameter of $5 \mathrm{~mm}$ arranged in two rows, with $4 \mathrm{~mm}$ between the rings. Subjects were asked to hold the red pen in their left hand and the black pen in their right hand, aiming at each circle in this row as quickly as possible without touching the bottom plate. The system automatically documented the completion time in seconds (s) and number of hits $(n)$ of both hands. The aiming index (ai) was calculated: ai $=n / t\left(s^{-1}\right)$. The test field of "Tapping" was two $40 \times 40 \mathrm{~mm}$ square surfaces. The subjects were asked to hold the red pen in their left hand and the black pen in their right hand to strike surfaces in turn as many times as possible within $32 \mathrm{~s}$. The number of accurate hits ( $n$ ) of both hands and total number of hits ( $n$ ) were recorded.

Statistical analyses

All statistical tests were performed with SPSS statistical software (version 22.0, SPSS, Inc., Chicago, IL, USA). The a level was set 0.05 in this study. The differences of sociodemographic data between the study and control groups were tested by independent sample t-test or chi-square test. Between-altitude and deployment duration differences were explored using analysis of variance (ANOVA), of altitude (LA, HA) by deployment duration (Group A, Group B, Group C). If the interaction effect of altitude and duration was significant at a level, simple effect analysis was used to further analyze the interaction effect. Otherwise, if the main effect of altitude or duration was significant at a level, least significant difference $t$ (LSD-t) 
test was used for post hoc comparison. Partial eta-square $\left(\eta_{p}{ }^{2}\right)$ was calculated as an effect size for ANOVA. Cohen's guidelines for $\eta_{p}{ }^{2}$ characterize effect size as large (0.14), medium (0.06), small (0.01) [20]. Because the current study was exploratory, Bonferroni adjusted a levels were not used for multiple comparisons [21].

\section{Results}

Demographic variables

There were no significant differences in demographic variables between HA group and LA group (see Table 1). 
Table 1

Demographic variables

\begin{tabular}{|c|c|c|c|}
\hline & HA group & LA group & $p$ value \\
\hline & $N=196$ & $N=192$ & \\
\hline Number of participants (\%) & & & 0.256 \\
\hline Group A & $28(14.3 \%)$ & $38(17.0 \%)$ & \\
\hline Group B & $28(14.3 \%)$ & $31(15.2 \%)$ & \\
\hline Group C & $140(71.4 \%)$ & $123(61.4 \%)$ & \\
\hline Mean age (SD) & & & \\
\hline Group A (year) & $20.68(2.93)$ & $20.63(1.44)$ & 0.932 \\
\hline Group B (year) & $20.82(2.07)$ & $20.71(1.22)$ & 0.799 \\
\hline Group C (year) & 24.99 (3.99) & $25.32(3.65)$ & 0.495 \\
\hline Mean service time (SD) & & & \\
\hline Group A (month) & $16.61(8.50)$ & $17.24(5.59)$ & 0.718 \\
\hline Group B (month) & $27.79(6.71)$ & $29.97(10.72)$ & 0.359 \\
\hline Group C (month) & $80.91(46.35)$ & $82.21(40.34)$ & 0.542 \\
\hline Mean deployment duration & & & \\
\hline Group A (month) & $11.29(2.39)$ & $10.50(1.45)$ & 0.102 \\
\hline Group B (month) & $21.29(4.24)$ & $20.42(4.46)$ & 0.449 \\
\hline Group C (month) & 79.08 (47.99) & $72.28(39.72)$ & 0.216 \\
\hline Educational level & & & 0.091 \\
\hline Secondary school & $47(24.0 \%)$ & $40(20.8 \%)$ & \\
\hline High school & $119(60.7 \%)$ & $108(56.3 \%)$ & \\
\hline Junior college & $23(11.7 \%)$ & $40(20.8 \%)$ & \\
\hline Undergraduate or above & $7(3.6 \%)$ & $4(2.1 \%)$ & \\
\hline Marital status (\%) & & & 0.082 \\
\hline single & $148(75.5 \%)$ & $159(82.8 \%)$ & \\
\hline married & $48(24.5 \%)$ & $33(17.2 \%)$ & \\
\hline
\end{tabular}

Note: HA: high altitude; LA: low altitude; Group A: deployment duration less than 1 year; Group B: deployment duration between 1 year and 2 years; Group C: deployment duration more than 2 years. 


\begin{tabular}{|c|c|c|c|}
\hline & HA group & LA group & $p$ value \\
\hline & $N=196$ & $N=192$ & \\
\hline Only child or not (\%) & & & 0.262 \\
\hline only child & $92(46.9 \%)$ & $79(41.1 \%)$ & \\
\hline not only child & $104(53.1 \%)$ & $113(58.9 \%)$ & \\
\hline
\end{tabular}

Simple reaction time

The interaction effect of altitude and duration was not significant on simple reaction time, $F(2,387)=$ $0.458, p=0.633, \eta_{p}^{2}=0.002$. The main effect of altitude was significant, $F(1,387)=18.041, p<0.001, \eta_{p}^{2}$ $=0.045$, such that the HA group participants had slower simple reaction time in comparison to LA participants. The main effect of duration was significant, $F(1,387)=3.300, p<0.038, n_{p}{ }^{2}=0.017$. Post hoc comparison showed that average reaction time was least in Group B (compared to Group A: $p=$ 0.065 ; compared to Group C: $p=0.013$ ), then in Group A (compared to Group C: $p=0.043$ ), finally group C (see Fig. 5a).

Bimanual coordination test

The interaction effect of altitude and duration was not significant on completion time in the bimanual coordination test, $F(2,387)=0.270, p=0.763, \eta_{p}^{2}=0.001$. The main effect of altitude was significant, $F(1$, $387)=2295.648, p<0.001, \eta_{p}{ }^{2}=0.857$, such that the HA group participants needed less time to complete the bimanual coordination test in comparison to LA participants, which was a medium difference judged by $\eta_{p}{ }^{2}$. The main effect of duration was not significant, $F(1,387)=2.009, p=0.136, \eta_{p}^{2}=0.010$ (see Fig. 5b).

The interaction effect of altitude and duration was not significant on error times in the bimanual coordination test, $F(2,387)=0.880, p=0.461, \eta_{p}^{2}=0.005$. The main effect of altitude was not significant, $F(1,387)=1.301, p=0.255, \eta_{p}^{2}=0.021$. The main effect of duration was significant, $F(1,387)=4.021, p$ $=0.019, n_{p}^{2}=0.021$. Post hoc comparison showed that average error times were fewest in Group $A$ (compared to Group B: $p=0.032$; compared to Group C: $p=0.006$, then in Group C (compared to Group B: $p=0.966$ ), finally group B (see Fig. $5 c$ ).

Fine motor dexterity test

The interaction effect of altitude and duration was not significant on completion time in the fine motor dexterity test, $F(2,387)=0.219, p=0.217, n_{p}{ }^{2}=0.008$. The main effect of altitude was not significant, $F(1$, 
$387)=1.434, p=0.232, \eta_{p}^{2}=0.004$. The main effect of duration was also not significant, $F(1,387)=$ 1.536, $p=0.217, \eta_{p}^{2}=0.008$ (see Fig. $5 d$ ).

The interaction effect of altitude and duration was not significant on drop times in the fine motor dexterity test, $F(2,387)=0.443, p=0.642, \eta_{p}^{2}=0.002$. The main effect of altitude was significant, $F(1$, $387)=5.980, p=0.015, n_{p}^{2}=0.015$, such that the HA group participants had more drop times in comparison to LA participants. The main effect of duration was significant, $F(1,387)=3.849, p=0.022$, $\eta_{\mathrm{p}}{ }^{2}=0.020$. Post hoc comparison showed that drop times was fewest in Group A (compared to Group B: $p=0.501$; compared to Group C: $p=0.005$ ), then in Group B (compared to Group C: $p=0.066$ ), finally group C (see Fig. 5e).

Aiming subtest in eye-hand coordination test

The interaction effect of altitude and duration was not significant on hit number with left hand in the aiming test, $F(2,387)=1.235, p=0.292, \eta_{p}^{2}=0.006$. The main effect of altitude was not significant, $F(1$, $387)=1.235, p=0.292, \eta_{p}^{2}=0.006$. The main effect of duration was also not significant, $F(1,387)=$ $0.724, p=0.485, \eta_{p}^{2}=0.004$ (see Fig. 5f).

The interaction effect of altitude and duration was not significant on completion time with left hand in the aiming test, $F(1,387)=0.444, p=0.642, \eta_{p}{ }^{2}=0.002$. The main effect of altitude was not significant, $F(2,387)=2.819, p=0.094, \eta_{p}^{2}=0.007$. The main effect of duration was also not significant, $F(1,387)=$ $0.617, p=0.540, \eta_{p}^{2}=0.003$ (see Fig. $5 \mathrm{~g}$ ).

The interaction effect of altitude and duration was not significant on left ai in the aiming test, $F(2,387)=$ $0.599, p=0.550, \eta_{p}^{2}=0.003$. The main effect of altitude was significant, $F(1,387)=13.205, p<0.001, \eta_{p}{ }^{2}$ $=0.033$, such that the HA group participants had better left ai in comparison to LA participants. The main effect of duration was not significant, $F(1,387)=0.340, p=0.712, n_{p}{ }^{2}=0.002$ (see Fig. 5 h).

The interaction effect of altitude and duration was not significant on hit number with right hand in the aiming test, $F(2,387)=0.244, p=0.784, \eta_{p}{ }^{2}=0.001$. The main effect of altitude was significant, $F(1,387)$ $=3.916, p=0.049, \eta_{p}{ }^{2}=0.010$, such that the HA group participants had more hits in comparison to LA participants. The main effect of duration was not significant, $F(1,387)=1.286, p=0.278, \eta_{p}{ }^{2}=0.007$ (see Fig. 5i).

The interaction effect of altitude and duration was not significant on completion time with left hand in the aiming test, $F(1,387)=0.247, p=0.782, \eta_{p}{ }^{2}=0.001$. The main effect of altitude was not significant, $F(2,387)=3.296, p=0.070, \eta_{p}^{2}=0.009$. The main effect of duration was also not significant, $F(1,387)=$ $0.455, p=0.635, \eta_{p}^{2}=0.002$ (see Fig. $5 \mathrm{j}$ ). 
The interaction effect of altitude and duration was not significant on right ai in the aiming test, $F(2,387)$ $=0.044, p=0.956, \eta_{p}{ }^{2}<0.001$. The main effect of altitude was not significant, $F(1,387)=2.609, p=0.107$, $\eta_{p}{ }^{2}=0.007$. The main effect of duration was not significant, $F(1,387)=0.193, p=0.824, \eta_{p}{ }^{2}=0.001$ (see Fig. 5k).

Tapping subtest in eye-hand coordination test

The interaction effect of altitude and duration was significant on hit number with left hand in the tapping test, $F(2,387)=3.327, p=0.037, \eta_{p}{ }^{2}=0.017$. Further simple effect analysis showed that the effect of duration was not significant among HA group, $p=0.129$. However, it was significant among LA group, $p=$ 0.008. In LA group, hit number was fewest in Group B (compared to Group A: $p=0.795$; compared to Group C: $p=0.015$ ), then in Group A (compared to Group C: $p=0.139$ ), finally group $C$. The effect of altitude was not significant among Group $A, p=0.791$. In Group B, hit number was more in HA group compared with LA group, $p=0.009$. The effect of altitude was not significant among Group $C, p=0.508$ (see Fig. 5l).

The interaction effect of altitude and duration was not significant on hit number with right hand in the tapping test, $F(2,387)=2.171, p=0.115, \eta_{p}^{2}=0.011$. The main effect of altitude was significant, $F(1$, $387)=10.477, p=0.001, n_{p}^{2}=0.027$, such that the HA group participants had more hits in comparison to LA participants. The main effect of duration was not significant, $F(1,387)=0.138, p=0.871, \eta_{p}{ }^{2}=0.001$ (see Fig. 5m).

The interaction effect of altitude and duration was significant on total hit number in the tapping test, $F(2$, $387)=3.099, p=0.016, \eta_{p}^{2}=0.016$. Further simple effect analysis showed that the effect of duration was not significant among HA group, $p=0.296$. However, it was significant among LA group, $p=0.036$. In LA group, hit number was fewest in Group B (compared to Group A: $p=0.801$; compared to Group C: $p=$ 0.052), then in Group A (compared to Group $C: p=0.342$ ), finally group $C$. The effect of altitude was not significant among Group $A, p=0.560$. In Group B, total hit number was more in HA group compared with LA group, $p=0.005$. The effect of altitude was not significant among Group $C, p=0.728$ (see Fig. $5 \mathrm{n}$ ).

\section{Discussion}

The border posts in Tibet depend highly on the supply transported by PMVOs. The completion of transportation tasks requires excellent driving skills based on psychomotor functions. Previous studies suggested that there was an adaptation process to HA which may have a key period. Thus, we carried out this study to investigate the effects of long-term deployment to HA on psychomotor abilities of PMVOs and the moderating effect of deployment duration. In this study, we found that PMVOs had slower simple reaction time and more error times in fine motor dexterity test. Surprisingly, we also found that PMVOs perform better in bimanual coordination test and both subtests of eye-hand coordination test. No consistency in time-related psychomotor performance change was observed in the present study. 
Simple reaction time is a sensitive indicator of driving ability [22, 23]. Previous studies mainly focused on the effect of acute exposure to HA on simple reaction time. Most studies showed that simple reaction time of subjects from LA became longer when participants were acute exposure to HA [24]. Chen et al. [19] found that the subjects showed prolonged responding time in the visual and auditory reaction time tests after chronic exposure (2 years) to HA. Consistent to these results, we found PMVOs showed significantly slower simple reaction time than their controls. Hypoxia caused by HA may contribute to the decrements of performance in reaction time tests [25]. Although the significant duration-related difference was observed in this study, there was no interaction of altitude and duration, which means that this tendency was not unique at HA. The age effect can explain this duration-related difference. Generally, longer deployment duration means older age among military motor vehicle operators. A number of studies suggested that there existed an age-related reaction slowing in healthy adults $[26,27]$. In this study, participants of Group A were nearly as old as Group B, while participants of Group C were much older than the other groups. The result was in line with the expectation from age effect: average reaction time of Group A were not statistically different from that of Group B, but reaction time of Group C was significantly slower in comparison to the rest two groups.

Bimanual hand coordination is of great importance in carrying out daily activities like driving, buttoning the shirt, picking up objects [28]. In this study, we found that HA group performed better in the bimanual coordination test than LA group, and Group A had the highest accuracy. The duration-related accuracy difference may result from different task strategy. Specifically, most participants of Group A were private, at the bottom of military ranks, who were more prone to choosing prudent task strategy in order to avoid mistakes. Although there is a negative association between age and bimanual coordination performance [28], Boisgontier et al. [29] found that bimanual coordination ability started declining from the age of 40 years. However, All participants in this study were younger than 35 years old ( $m e a n=23.71, S D=3.93$ ), thus the age effect cannot explain the duration-related accuracy difference. Boisgontier et al. [29] suggested that the decline of bimanual coordination performance was associated with adverse aging effect on primary sensorimotor cortex and primary motor cortex in older adults. Interestingly, reduced white matter density/volume of primary motor cortex (BA 4) was found after high-altitude exposure [30], which means residence at HA may have a hazardous effect on certain brain region. Thus, it is reasonable to speculate that long-term exposure to HA may have an adverse effect on primary motor cortex, which may in turn affect bimanual coordination performance. However, the results showed that HA group performed better. Firstly, this result did not deny the altitude-induced brain impairments and declining performance observed by previous studies $[13,14,19]$. Secondly, many different mechanisms may contribute to mitigating the altitude-induced impairments. Adaptive process may relieve the adverse effect of hypoxia at HA, in which hypoxia-inducible factor (HIF) pathway plays an important role [31, 32]. In addition, cognitive reserve process can alleviate brain impairments caused by HA [33]. Thirdly, the Yerkes-Dodson law may explain why HA group performed better in the bimanual coordination test [34]. According to the Yerkes-Dodson law, the bimanual coordination test was an easy task for the participants, so high mental load was required to perform this task better. The mental load was internally (motivation) and externally (environmental stressors) induced. In this study, PMVOs and LMVOs were all highly 
motivated service men. On the other hand, HA was a big environmental stressor for PMVOs, so HA group had higher mental load which resulted in better performance. Similar phenomenon was also found among people working in other extreme environments, such as Antarctic expeditioners [35].

Compared with the LA group, HA group completed the fine motor dexterity test with more errors at the same speed. In addition, Group A showed the fewest error times. Two reason may explain this result. Firstly, LMVOs may choose a prudent task strategy to avoid mistakes. Secondly, more error times in PVMOs resulted from impaired fine motor dexterity. Rogers et al. [36] suggested that fatigue could induce fine motor dexterity decrement. Many studies demonstrated that exposure to HA was associated with fatigue $[37,38]$. Thus, fatigue may be a mediator of the effect of HA on fine motor dexterity.

Eye-hand coordination is necessary for many daily tasks [39]. In this study, PMVOs performed better in eye-hand coordination test. Specifically, PMVOs had better left aiming index and more hits with right hand in the aiming test. They also had more hits with left hand and more total hits in the tapping test. Similarly, fatigue was also found to be associated with the impairments of eye-hand coordination[36]. Thus, it was expected that HA group should have a poorer performance. But, the opposite was observed in the present study. This phenomenon can also be explained by the Yerkes-Dodson law mentioned before. More interestingly, the duration moderated the effect of altitude on tapping test. But, only in Group $B$ (deployment duration between 1 year and 2 years), the altitude-induced difference was statistically significant. On the other hand, there was no significant differences among 3 duration groups in HA group. These results suggested that no special time-related changing curve was observed among PMVOs, which was expected based on previous studies $[17,19]$. The probable reason may be that the critical time point passed among participants in HA group. The average deployment duration of Group A at HA was 11.29 months, while the observed critical point may be 7 months or 1 year. So, it was possible that the adverse effect of altitude had overweighed adaptation and other protective factors in all selected PMVOs. Another possible reason was the effect of selection and promotion mechanism in army. Only those well-behaved PMVOs can stay in the army after the end of their service, which means that PMVOs with poor eye-hand coordination could be weeded out. Thus, the selection effect may confound the moderating effect of HA deployment duration. These two reason can also explain why no duration-related change was observed among PMVOs in other psychomotor test.

Several limitations of the present study must be addressed. First, this was a cross-sectional study. Thus, the results of the HA deployment duration related effect was not conclusive. Further longitudinal repeated measurement design study should be conducted. Second, the psychomotor tests used in this study was too easy for young healthy well-trained service men. Thus, the motivation level and ceiling effect may affect the reliability of the results.

\section{Conclusion}

This is the first study to investigate the effect of chronic exposure to HA on psychomotor functions and the moderating effect of deployment duration. In this study, we found that prolonged exposure to HA may 
cause psychomotor slowing and declining fine motor dexterity. But, the moderating effect of deployment duration was not supported by this study.

\section{Abbreviations}

PMVOs

Plateau motor vehicle operators; HA:High altitude; LMVOs:Lowland motor vehicle operators; LA:Low altitude; ANOVA:Analysis of variance; STIFECNU:Scientific \& Teaching Instruments Factory of East China Normal University; SRT:Simple reaction time; MLS:Motor Performance Series; Ai:Aiming index; LSD-t test:Least significant difference t test; $\eta_{p}{ }^{2}$ :Partial eta-square; HIF:Hypoxia-inducible factor

\section{Declarations}

\section{Ethics approval and consent to participate}

The protocols were approved by the Review Board of the Second Military Medical University. Written informed consent was obtained from each subject before participating in this study.

\section{Consent for publication}

Not applicable.

\section{Availability of data and materials}

The datasets generated and/or analyzed during the current study are not publicly available due to the potential sensitive nature of military healthcare data.

\section{Competing interests}

The authors declare that they have no competing interests.

\section{Funding}

12th Five-Year Plan, Grant/Award Number: AWS12J002; People's Liberation Army, China

\section{Authors' contributions}

LP and XH developed the study design. LP collected the data. LP, ZT and JH analyzed and interpreted the data. ZT and JH conducted a literature search and wrote the manuscript. All authors read and approved the final manuscript. 


\section{Acknowledgements}

Thank a lot to my beloved wife and hard-working colleague: Jing-wen He.

\section{References}

1. 10.1016/j.psychres.2009.02.013

De las Cuevas C, Ramallo Y, Sanz EJ. Psychomotor performance and fitness to drive: The influence of psychiatric disease and its pharmacological treatment. Psychiatry Res [Internet]. Elsevier Ltd; 2010;176:236-41. Available from: http://dx.doi.org/10.1016/j.psychres.2009.02.013.

2. $10.1016 /$ j.forsciint.2015.04.024

Giorgetti R, Marcotulli D, Tagliabracci A, Schifano F. Effects of ketamine on psychomotor, Sensory and cognitive functions relevant for driving ability. Forensic Sci Int [Internet]. Elsevier Ireland Ltd; 2015;252:127-42. Available from: http://dx.doi.org/10.1016/j.forsciint.2015.04.024.

3. Leufkens TRM, Vermeeren A, Smink BE, Van Ruitenbeek P, Ramaekers JG. Cognitive, psychomotor and actual driving performance in healthy volunteers after immediate and extended release formulations of alprazolam $1 \mathrm{mg}$. Psychopharmacology. 2007;191:951-9.

4. Brunnauer A, Buschert V, Fric M, Distler G, Sander K, Segmiller F, et al. Driving performance and psychomotor function in depressed patients treated with agomelatine or venlafaxine. Pharmacopsychiatry. 2015;48:65-71.

5. Vuurman EFPM, Uiterwijk MMC, O'Hanlon JF, Rosenzweig P. Effects of mizolastine and clemastine on actual driving and psychomotor performance in healthy volunteers. Eur J Clin Pharmacol. 1994;47:253-9.

6. Yan X. Cognitive impairments at high altitudes and adaptation. High Alt Med Biol. 2014;15:141-5.

7. Berry DT, McConnell JW, Phillips BA, Carswell CM, Lamb DG, Prine BC. Isocapnic hypoxemia and neuropsychological functioning. J Clin Exp Neuropsychol Off J Int Neuropsychol Soc. 1989;11:24151.

8. Bolmont B, Thullier F, Abraini JH. Relationships between mood states and performances in reaction time, psychomotor ability, and mental efficiency during a 31-day gradual decompression in a hypobaric chamber from sea level to $8848 \mathrm{~m}$ equivalent altitude. Physiol Behav [Internet]. 2000;71:469-76. Available from: http://ovidsp.ovid.com/ovidweb.cgi?

$\mathrm{T}=\mathrm{JS} \& \mathrm{PAGE}=$ reference\&D$=$ emed5\&NEWS $=\mathrm{N} \& A N=2001086405$.

9. Davis JE, Wagner DR, Garvin N, Moilanen D, Thorington J, Schall C. Cognitive and psychomotor responses to high-altitude exposure in sea level and high-altitude residents of Ecuador. J Physiol Anthropol. 2015;34:2-5.

10. Shehu L, Min F, Mingfu K, Zhongchun W. A cross-cultural study of intellectual and nonintellectual factors influencing mathematical ability in Tibetan and Han students. Chinese Educ Soc. 2001;34:59-70. 
11. Virués-Ortega J, Buela-Casal G, Garrido E, Alcázar B. Neuropsychological functioning associated with high-altitude exposure. Neuropsychol Rev. 2004;14:197-224.

12. Tronick EZ, Thomas RB, Daltabuit M. The Quechua Manta Pouch: A Caretaking Practice for Buffering the Peruvian Infant Against the Multiple Stressors of High Altitude. Child Dev. 1994;65:1005-13.

13. Yan X, Zhang J, Gong Q, Weng X. Prolonged high-altitude residence impacts verbal working memory: An fMRI study. Exp Brain Res. 2011;208:437-45.

14. 10.1016/j.bandc.2011.06.002

Yan X, Zhang J, Gong Q, Weng X. Adaptive influence of long term high altitude residence on spatial working memory: An fMRI study. Brain Cogn [Internet]. Elsevier Inc.; 2011;77:53-9. Available from: http://dx.doi.org/10.1016/j.bandc.2011.06.002.

15. Gamponia MJ, Babaali H, Yugar F, Gilman RH. Reference values for pulse oximetry at high altitude. Arch Dis Child. 1998;78:461-5.

16. Hogan AM, Virues-Ortega J, Botti AB, Bucks R, Holloway JW, Rose-Zerilli MJ, et al. Development of aptitude at altitude. Dev Sci. 2010;13:533-44.

17. Zhang J, Liu H, Yan X, Weng X. Minimal effects on human memory following long-term living at moderate altitude. High Alt Med Biol. 2011;12:37-43.

18. Hill CM, Dimitriou D, Baya A, Webster R, Gavlak-Dingle J, Lesperance V, et al. Cognitive performance in high-altitude Andean residents compared with low-altitude populations: From childhood to older age. Neuropsychology. 2014;28:752-60.

19. Chen X, Zhang Q, Wang J, Liu J, Zhang W, Qi S, et al. Cognitive and neuroimaging changes in healthy immigrants upon relocation to a high altitude: A panel study. Hum Brain Mapp. 2017;38:3865-77.

20. Cohen J. Statistical Power Analysis for the Behavioral Sciences. New York: Routledge Academic; 1988.

21. Rothman KJ. No adjustments are needed for multiple comparisons. Epidemiology. 1990;1:43-6.

22. Philip P, Taillard J, Quera-Salva MA, Bioulac B, Åkerstedt T. Simple reaction time, duration of driving and sleep deprivation in young versus old automobile drivers. J Sleep Res. 1999;8:9-14.

23. 10.1016/j.trf.2013.09.007

Ferreira IS, Simões MR, Marôco J. Cognitive and psychomotor tests as predictors of on-road driving ability in older primary care patients. Transp Res Part F Traffic Psychol Behav [Internet]. Elsevier Ltd; 2013;21:146-58. Available from: http://dx.doi.org/10.1016/j.trf.2013.09.007.

24. Martin K, McLeod E, Périard J, Rattray B, Keegan R, Pyne DB. The Impact of Environmental Stress on Cognitive Performance: A Systematic Review. Hum Factors. 2019;61:1205-46.

25. Dart T, Gallo M, Beer J, Fischer J, Morgan T, Pilmanis A. Hyperoxia and hypoxic hypoxia effects on simple and choice reaction times. Aerosp Med Hum Perform. 2017;88:1073-80.

26. 10.1016/j.exger.2015.08.005

Arnold P, Vantieghem S, Gorus E, Lauwers E, Fierens Y, Pool-Goudzwaard A, et al. Age-related differences in muscle recruitment and reaction-time performance. Exp Gerontol [Internet]. Elsevier 
B.V.; 2015;70:125-30. Available from: http://dx.doi.org/10.1016/j.exger.2015.08.005.

27. Tam A, Luedke AC, Walsh JJ, Fernandez-Ruiz J, Garcia A. Effects of reaction time variability and age on brain activity during Stroop task performance. Brain Imaging Behav. 2015;9:609-18.

28. Shetty AK, Vinutha Shankar MS, Annamalai N. Bimanual coordination: Influence of age and gender. J Clin Diagnostic Res. 2014;8:15-6.

29. 10.1016/j.neurobiolaging.2018.01.016

Boisgontier MP, Cheval B, van Ruitenbeek P, Cuypers K, Leunissen I, Sunaert S, et al. Cerebellar gray matter explains bimanual coordination performance in children and older adults. Neurobiol Aging [Internet]. Elsevier Inc.; 2018;65:109-20. Available from:

https://doi.org/10.1016/j.neurobiolaging.2018.01.016.

30. Paola MD, Bozzali M, Fadda L, Musicco M, Sabatini U, Caltagirone C. Reduced oxygen due to highaltitude exposure relates to atrophy in motor-function brain areas. Eur J Neurol. 2008;15:1050-7.

31. Bigham AW, Lee FS. Human high-altitude adaptation: Forward genetics meets the HIF pathway. Genes Dev. 2014;28:2189-204.

32. Simonson TS. Altitude Adaptation: A Glimpse Through Various Lenses. High Alt Med Biol. 2015;16:125-37.

33. Stern Y. Cognitive reserve. Neuropsychologia. 2009;47:2015-28.

34. Calabrese EJ. Stress biology and hormesis: The Yerkes-Dodson Law in psychology - A special case of the hormesis dose response. Crit Rev Toxicol. 2008;38:453-62.

35. Defayolle M, Boutelier C, Bachelard C, Rivolier J, Taylor AJW. The stability of psychometric performance durii the international biomedical expedition to the antarctic (IBEA). J Human Stress. 1985;11:157-60.

36. Rogers CM, Saway B, Busch CM, Simonds GR. The Effects of 24-Hour Neurosurgical Call on Fine Motor Dexterity, Cognition, and Mood. Cureus. 2019;11.

37. Gudjonsdottir M, Appendini L, Baderna P, Purro A, Patessio A, Vilianis G, et al. Diaphragm fatigue during exercise at high altitude: The role of hypoxia and workload. Eur Respir J. 2001;17:674-80.

38. Marillier M, Arnal PJ, Le Roux Mallouf T, Rupp T, Millet GY, Verges S. Effects of high-altitude exposure on supraspinal fatigue and corticospinal excitability and inhibition. Eur J Appl Physiol. Springer Berlin Heidelberg; 2017;117:1747-61.

39. Abrams RA, Meyer DE, Kornblum S. Eye-Hand Coordination: Oculomotor Control in Rapid Aimed Limb Movements. J Exp Psychol Hum Percept Perform. 1990;16:248-67.

\section{Figures}




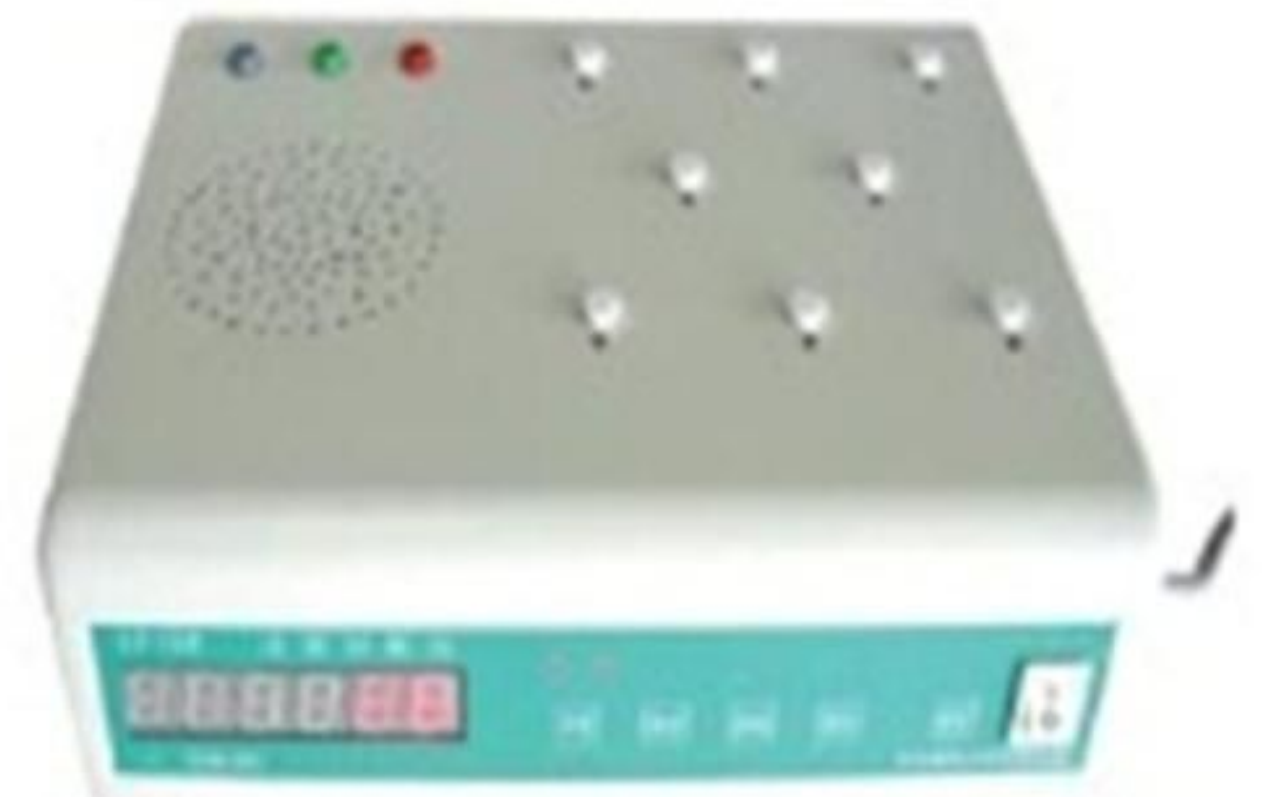

Figure 1

Reaction time measuring instrument (EP708A)

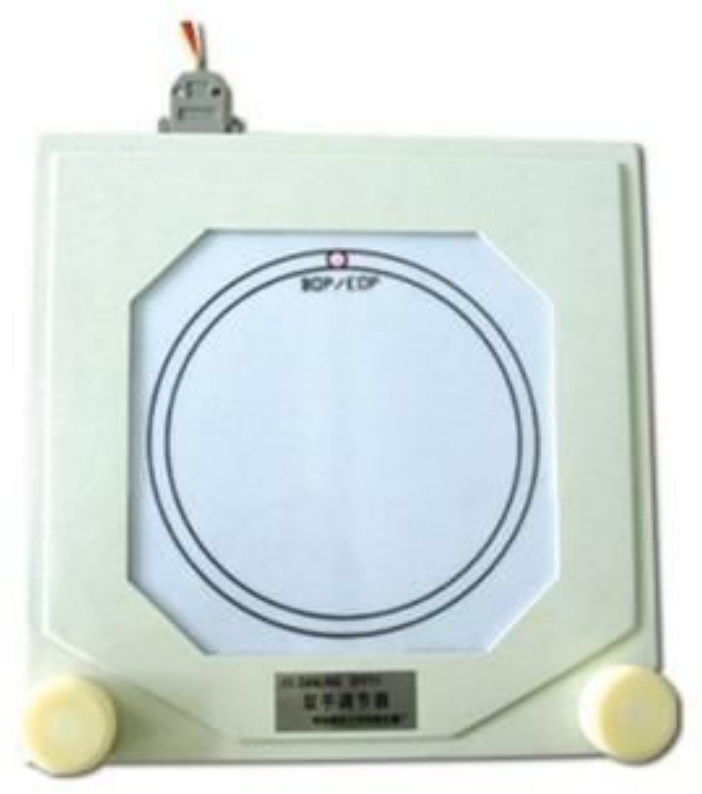

Figure 2

Bimanual regulator (EP711) 


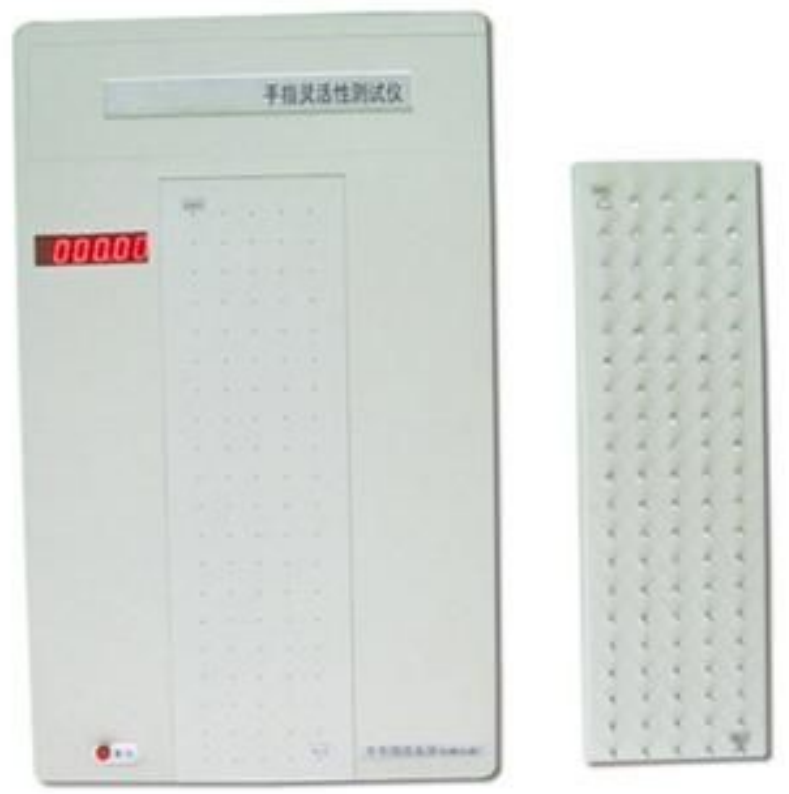

Figure 3

Finger dexterity measuring instrument (EP109)

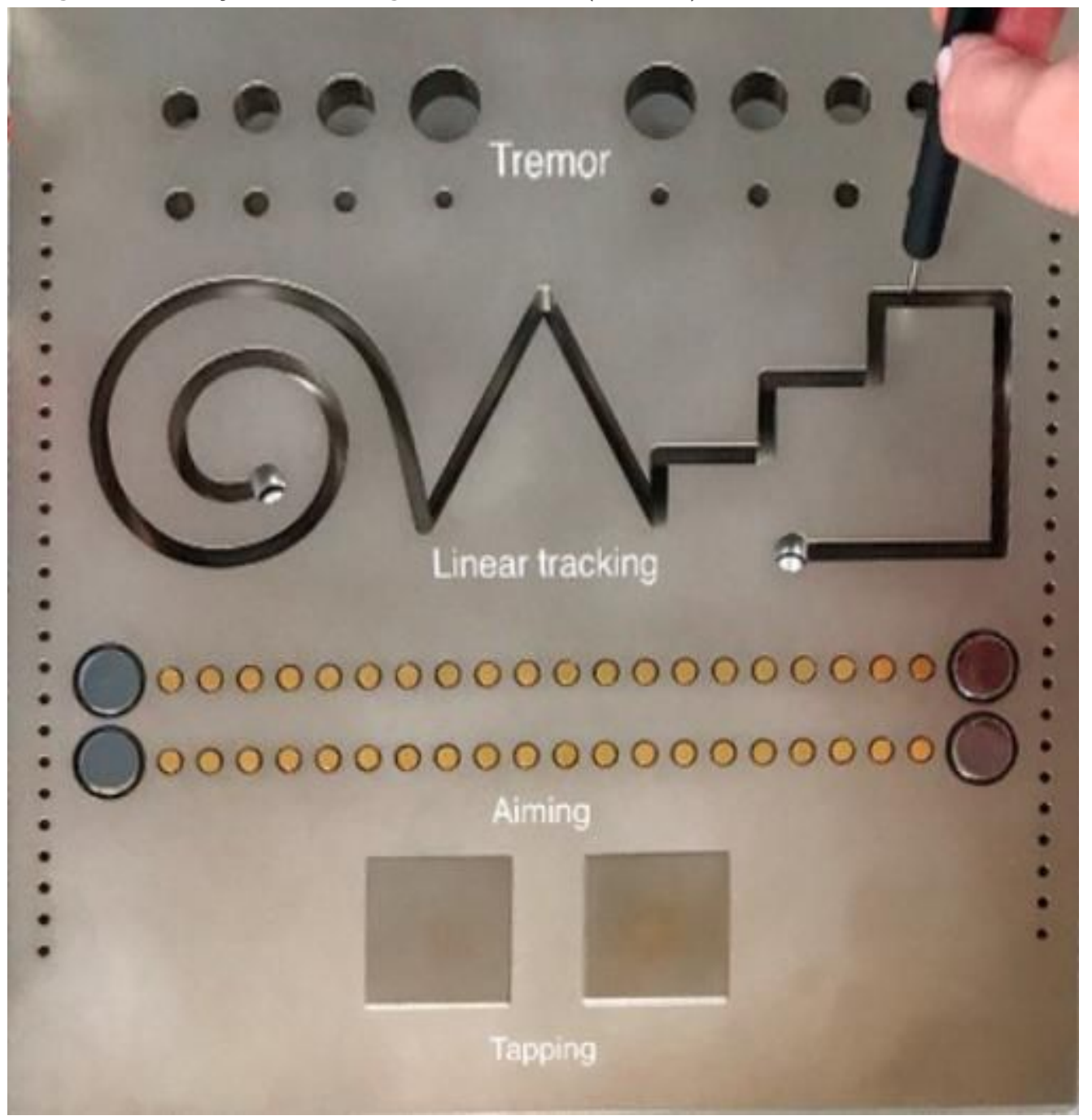

Figure 4 
Motor Performance Series (MLS) of the Vienna Test System
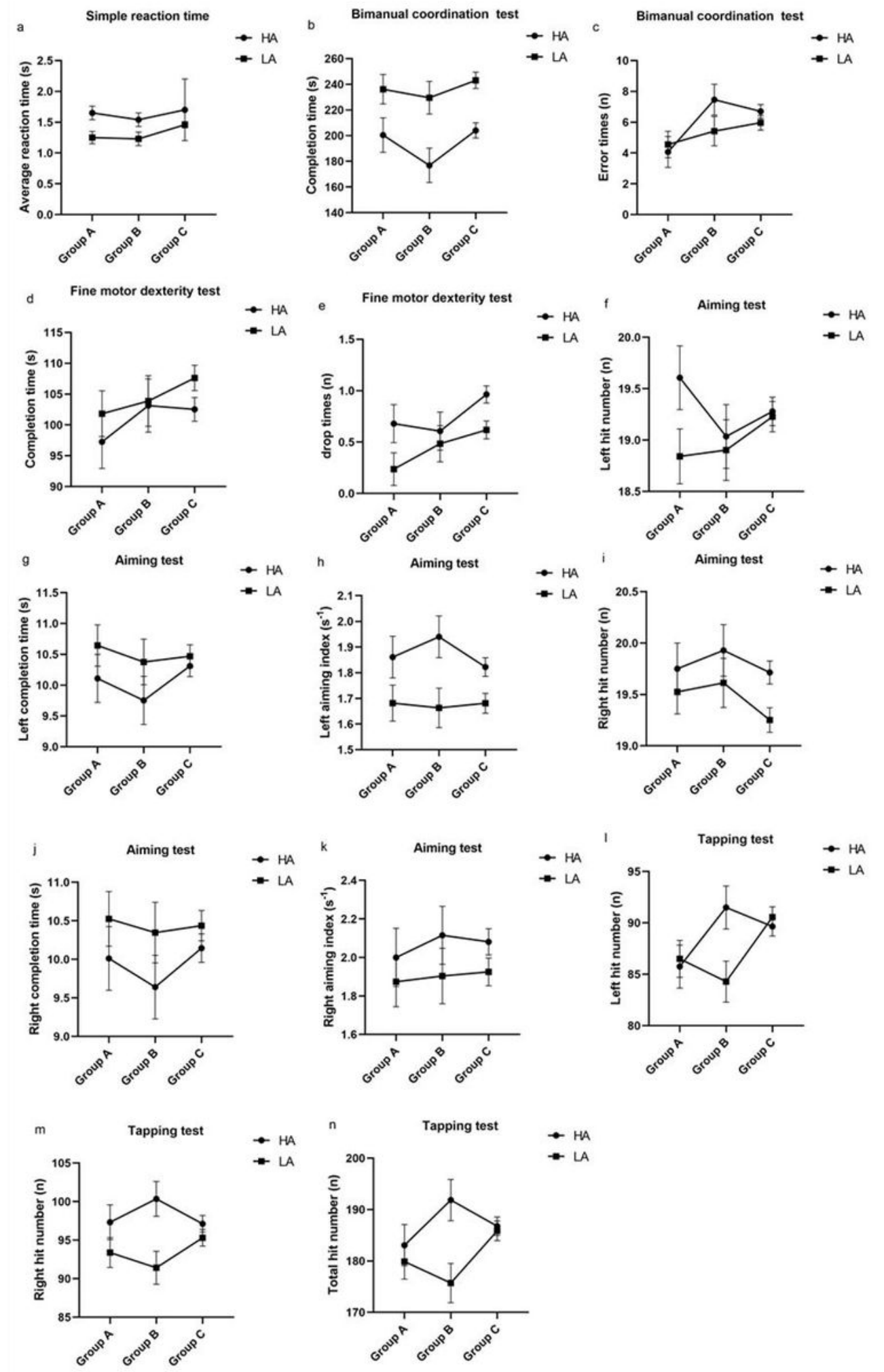

\section{Figure 5}

Psychomotor functions test results by altitude and duration group. HA: high altitude; LA: low altitude; Group A: deployment duration less than 1 year; Group B: deployment durationbetween 1 year and 2 years; Group C: deployment duration more than 2 years. 